\title{
A RECEPÇÃO DA ERUDIÇÃO ISLÂMICA NA DIVINA COMÉDIA SOB A PERSPECTIVA DE MIGUEL ASÍN PALACIOS (1871-1944)
}

\author{
Elaine Cristina Senko*
}

\begin{abstract}
ASÍN PALACIOS, Miguel. Islam and The Divine Comedy. Tradução de Harold Sunderland. New Delhi: Goodword Books, 2a. ed., 2002.
\end{abstract}

Miguel Asín Palacios (1871-1944), renomado arabista espanhol, dedicou mais de vinte e cinco anos de sua vida em investigar a filosofia e a religiosidade no pensamento islâmico medieval, em especial sobre a cultura desenvolvida em Al-Andaluz. Asín Palacios iniciou seus estudos em Letras no meio eclesiástico, mas depois entrou em contato com as leituras da vertente Oriental com o mestre de estudos arábicos da Espanha, Julián Ribera. Essa aproximação foi essencial na carreira de Asín Palacios, pois a partir desse momento ele revela uma busca por compreender as pesquisas sobre o Oriente e se interessa pelos métodos de pesquisa histórica.

\footnotetext{
Mestranda pelo Programa de Pós-Graduação em História UFPR. Membro discente do Núcleo de Estudos Mediterrânicos. Orientadora: Professora Doutora Marcella Lopes Guimarães.
} 
Destarte, Asín Palacios se dedicou principalmente a entender a filosofia árabe, ou seja, a falsafa e sua relação com textos de autores cristãos. E foi por essa via que o pesquisador espanhol encontrou importantes conexões filosóficas, por exemplo: a teologia de Averroés nos escritos de Santo Tomás de Aquino, de Ibn Arabi de Murcia em Raimundo Lull, somente para citar alguns. Além disso, foi atraído pelas pesquisas sobre Ibn Massara, Ibn Hazm e pelo sufismo.

Nesta obra, Islam and The Divine Comedy, Asín Palacios analisa a influência de modelos de pensamento islâmico na Divina Comédia de Dante Alighieri (1265-1321). O paralelo traçado pelo pesquisador é estabelecido entre as ahadiths, sobre a elaboração de Ibn Arabi e o cruzamento de informações com a obra do poeta florentino. Essa experiência inclusive despertou a curiosidade de críticos da literatura da história. Os chamados "dantistas italianos", quando da publicação da obra de Asín Palácios, tiveram muita dificuldade em reconhecer que estudos islâmicos poderiam estar presentes na composição da Divina Comédia, produção simbólica da cultura cristã medieval.

A tese principal apresentada neste livro de Asín Palacios se baseia nas duas influências presentes na Divina Comédia de Dante Alighieri: a inspiração na hadith, na qual são relatados fatos sobre a vida do Profeta Muhammad e sua ascensão (mi'raj) e as visões de cunho espiritual de Ibn Al-Arabi. É esta pesquisa que causou tanta movimentação de críticas entre italianos nacionalistas, clérigos da Igreja Romana e de outros estudiosos que não admitiam a inspiração 
islâmica nessa obra de Dante. Asín Palacios, entretanto, enfrentou toda essa tormenta e, enfim, obteve o apoio da maioria dos estudiosos da Europa e da América.

A obra Islam and The Divine Comedy possui quatro partes, a primeira é sobre a viagem noturna e a ascensão do Profeta na qual se pode conectar isso com os dados da Divina Comédia, por exemplo, quando das similaridades entre Virgilio em Dante com a aparição de Gabriel ao Profeta Muhammad. O essencial é que as figuras de Virgilio e Gabriel negam as futilidades do mundo terreno. Esse conceito moral para Asín Palacios é oriundo do pensamento sufi, em particular de Murcian Ibn Arabi. A comparação entre a Divina Comédia e o pensamento islâmico possui o seguinte panorama: a arquitetura geral e a estrutura étnica do inferno e do paraíso; a descrição das torturas e recompensas; as linhas gerais da ação dramática; a significação alegórica; e o intrínseco valor literário.

$\mathrm{Na}$ segunda parte da obra abordada nessa resenha, Asín Palacios examina as comparações da Divina Comédia com outras fontes islâmicas além das ahadiths. Nesse momento foi necessário analisar o poema de Dante em cinco partes - limbo, inferno, purgatório, paraíso terreno e o paraíso celestial. O limbo de Dante era habitado por crianças que morrem inocentemente sem que fossem batizadas, homens e mulheres da época pagã, seguidores de Muhammad, famosos poetas, filósofos (onde se encontra Avicena e Averroés) e heróis míticos. O limbo islâmico, atestado pela autoridade dos estudos de Algazel, demonstra uma aproximação com 
as divisões postas por Dante em sua obra. O inferno em Dante (onde se encontraria o próprio Profeta Muhammad) e nas concepções islâmicas está intrinsecamente relacionado com a queda de Lúcifer e a propagação da revolta por sua parte. As almas que perpassam pelo purgatório, tanto no caso islâmico quanto cristão, são julgadas por seus pecados. No entanto, o que é típico no relato de purgatório islâmico é a tristeza e a dor advinda da moral, essa descrição se encontra tanto nas hadiths quanto em diversos escritos de pensadores muçulmanos. A provável localização para o chamado paraíso terreno, na concepção de Dante, seria em uma alta montanha, surgindo no meio de uma ilha (talvez próximo à Jerusalém). Por outro lado, de acordo com o Islã, o paraíso terrestre seria também em uma alta montanha, na parte central de uma ilha, mas no Oceano Índico. O paraíso celestial necessita para Asín Palacios de uma explicação advinda da cosmologia desenvolvida por Ibn Arabi, pois como na parte do inferno islâmico e dantesco, aqui também se verifica a série de círculos e esperas concêntricas (no caso do paraíso islâmico, círculos de condução da terra até o Divino Trono).

O paraíso escolhido por Ibn Arabi se situa entre o céu das estrelas fixas e o que podemos chamar de primum mobile. Aqui, outras oito esferas concêntricas, crescem uma debaixo da outra, representando as oito mansões do paraíso celestial. Essas aparecem na seguinte ordem: 1. O lugar da graça; 2. A mansão da perseverança; 3. O lugar da paz; 4. O jardim da eternidade; 5. O jardim do refúgio; 
6. O jardim da iluminação; 7. O jardim do paraíso; 8. O Jardim do Éden. Cada uma dessas oito esferas é dividida em vários portões, isso também corresponde ao que aparece na Divina Comédia.

A terceira parte da obra de Asín Palacios nos apresenta as influências do pensamento islâmico na literatura cristã precursora da Divina Comédia. A crença na imortalidade da alma, do desejo natural do homem em conhecer os segredos pós-morte e sobre a jornada fantástica entre a morte e o além são temas do pensamento cristão medieval. Os estudiosos de Dante fundamentam, segundo Asín Palacios, que essas são as bases para que Dante criasse seu grandioso poema. Um dos exemplos citados pelo arabista espanhol é a Visão de Alberico, nesta o monge protagonista é o homônimo que narra sua jornada para além da vida por meio de seu inconsciente. Essa é uma das principais "visões" que os estudiosos de Dante afirmam ser a base de inspiração para a criação da Divina Comédia. Todavia, Asín Palacios infere a questão da possibilidade de Dante conhecer que na própria visão do referido monge haveria elementos de pertencimento ao mundo religioso islâmico.

As lendas sobre o paraíso antes da criação do poema dantesco representavam um local permeado pelo materialismo. Dante, portanto, recriou um ambiente de traços espirituais e etéreos, além da assimilação, conforme Asín Palacios, do paradigma islâmico. Assim sendo, outros são os modelos das lendas inspiradoras da Divina Comédia de Dante Alighieri, que pertencem ao estilo de "contos de viagens". Essas lendas possuem características que as 
identificam e podem ser agrupadas: são contos de viagens maravilhosas em terras fantásticas; os protagonistas são aventureiros/conquistadores ou santos, que são invariavelmente muito mais míticos do que históricos. Essas "viagens", afirma Asín Palacios, se deparam em algum momento com o paraíso na terra ou com a famosa lenda da fonte da juventude. Aproximadamente na mesma época de produção desses relatos de viagens no Ocidente, cerca do século X, também estava acontecendo o florescimento da cultura no Oriente próximo ao Golfo Pérsico e ao Oceano Índico. Essa produção de caráter islâmico estava encontrando grande popularidade, e conforme Asín Palacios, poderia ter ocorrido uma transmissão dessa sabedoria para o Ocidente, porque as lendas orientais desse momento possuíam as mesmas características daquelas produzidas em território cristão. As estórias orientais possuíam as aventuras em terras fabulosas, os protagonistas raramente eram indivíduos históricos (como os heróis das lendas cristãs).

Na quarta parte da obra de Asín Palacios podemos conferir as probabilidades de transmissão de modelos islâmicos especificamente para a Divina Comédia. Asín Palacios apresenta três questões pertinentes a serem levantadas: primeiro, é possível alegar cópia de modelos e ocorre tal conexão numa pesquisa comum? A prioridade seria a imitação ou cópia? E poderia acontecer a cópia dos escritos de Ibn Arabi por Dante Alighieri? Segundo Asín Palacios o que importa são as duas primeiras perguntas, a que menos interessa é a terceira... 
A resposta para essas questões poderia ser primeiro entender a via de acesso ao conhecimento que chegou até Dante. A evidência de tal recepção poderia se encontrar na sociedade medieval cristã, pelo seu contato com os muçulmanos, adquirindo dessa maneira conhecimento e concepções orientais. Assim, Dante poderia ter direta ou indiretamente pesquisado materiais de fontes islâmicas e as colocado no poema.

Deste modo podemos compreender que as trocas políticas e culturais entre muçulmanos e cristãos tiveram um caminho especial até chegar ao tempo de Dante Alighieri. Se nos voltarmos, tal como Asín Palacios, para a educação recebida por Dante podemos encontrar canais que podem verificar a influência islâmica. Dante recebeu treinamento literário de Brunetto Latini, um mestre em conhecimento enciclopédico e membro notário de Florença. Esse mestre de Dante utilizava fontes de Averroés e Avicena, por exemplo, e este último sábio árabe traduziu a Ética a Nicômaco de Aristóteles. Além disso, Latini muitas vezes, ministrava aulas que não possuíam embasamento teórico em estudos cristãos ou clássicos, mas sim ligados aos estudos orientais. Para se ter uma idéia do prestigio da cultura islâmica no tempo de Dante, um contemporâneo seu, o pensador Roger Bacon indicava que os defeitos dos cristãos estavam precisamente em sua ignorância sobre as línguas semíticas e a respeito da ampla ciência desenvolvida por mestres islâmicos.

O resultado dessa miscigenação cultural na obra-prima de Dante Alighieri, Divina Comédia, sob esse olhar inovador de Miguel 
Asín Palacios amplia o entendimento das relações das trocas da forma erudita entre o universo cristão e o islâmico. Nisso pautado, concordamos com o arabista espanhol quando afirma que Dante possuía respeito pelos sábios árabes e os utilizava em seus trabalhos, tais como: os astrônomos (Albumazar, Alfraganius e Alpetragius) e os grandes filósofos (Alfarabius, Avicena, Algazel e Averróis). Acrescenta-se a isso o modo especial de Dante quando retrata homens como o próprio Saladino.

A conexão intermitente estabelecida por Asín Palacios entre a Divina Comédia e a filosofia islâmica envolve os escritos de Ibn Arabi. Em Vita Nuova e na Divina Comédia também se verificam descrições feitas por Dante sobre a interpretação de sonhos, tal como Ibn Arabi analisava a ocorrência deles. Dante Alighieri, portanto, era um homem de seu tempo, pertencia a uma sociedade rica em cultura que era resultado de vários caminhos da erudição, e um deles era a herança cultural islâmica. Essa recepção da erudição em Florença e no caso de Dante era um paradigma próprio, e isso passou a ser revelado pela percepção dos estudos realizados por Miguel Asín Palacios. Estudos esses que devem ser retomados por aqueles que se interessam pelo saber islâmico e pela pesquisa histórica. 